\title{
Correction to: HYPE: A System of Hyperintensional Logic (with an Application to Semantic Paradoxes)
}

\author{
Hannes Leitgeb ${ }^{1}$ \\ Published online: 3 January 2019 \\ (C) Springer Nature B.V. 2019
}

\section{Correction to: J Philos Logic https://doi.org/10.1007/s10992-018-9467-0}

The original version of the article unfortunately contained a mistake. The author missed to mention the support by a EU-funded research network that he is involved in. See below.

This work was supported by the Marie-Sklodowska-Curie Innovative Training Network DIAPHORA (Project Number 675415, HORIZON 2020-MSCAITN_2015).

Publisher's Note Springer Nature remains neutral with regard to jurisdictional claims in published maps and institutional affiliations.

The online version of the original article can be found at https://doi.org/10.1007/s10992-018-9467-0.

Hannes Leitgeb

Hannes.Leitgeb@1mu.de

1 LMU Munich, Geschwister-Scholl-Platz 1, 80539 Munich, Germany 